\title{
El alcance de la reforma operada en la Ley Estatal 6/1998, sobre régimen del suelo y valoraciones, por la Ley 10/2003, de 20 de Mayo, de medidas urgentes de liberalización en el sector inmobiliario
}

\author{
Antonio Alfonso Pérez Andrés \\ Profesor Titular de Derecho Administrativo \\ Universidad de Sevilla
}

\section{INTRODUCCIÓN}

El pasado 21 de Mayo de 2003 se ha publicado en el BOE una nueva Ley que reforma en cinco artículos la Ley estatal 6/1998, de 13 de abril, sobre Régimen del Suelo y Valoraciones. La espiral de reformas legislativas y sentencias del Tribunal Constitucional en la que se haya inmerso el ordenamiento jurídico urbanístico parece no tener fin.

En este caso la reforma ha venido de la mano de una Ley ordinaria, con lo que no se ha hecho uso de la fórmula del Decreto-Ley que con tanta profusión se había venido utilizando para realizar retoques en la normativa estatal urbanística, como es el caso del Real Decreto-Ley 4/2000, de 23 de junio, que curiosamente tenía exactamente el mismo nombre que ahora se emplea para la nueva Ley reformadora, la 10/2003, de 20 de mayo, de Medidas Urgentes de Liberalización en el Sector Inmobiliario y Transportes, aunque distinto contenido como ahora veremos.

\section{MOTIVACIÓN DE LA REFORMA}

Según puede leerse en la exposición de motivos de la Ley su objetivo fundamental es incidir de manera inmediata en el comportamiento de los distintos agentes económicos para estimular la competencia, conseguir una mejor asignación de los recursos y, en definitiva, influir muy positivamente sobre el nivel de precios. 
La preocupación que muestra el texto por la situación del sector inmobiliario es grande. Se insiste en que la imparable elevación de los precios de la vivienda está generada por el fuerte crecimiento de la demanda y la incidencia del precio del suelo en los productos inmobiliarios. Y, para solucionar este segundo problema, se mantiene, como ya se había hecho en normas anteriores, que el precio elevado del suelo responde a la escasez de suelo urbanizable y urbanizado. Cree por tanto la norma que la solución "mágica" estará en un fuerte incremento de la oferta de suelo, y para ello introduce mayor flexibilidad en algunas previsiones normativas que entiende pueden limitarla.

Junto a este tema, se aprovecha la ocasión para aclarar también los métodos aplicables en las valoraciones de suelos urbanos y urbanizables, pues se considera que con arreglo a los artículos hasta ahora vigentes se podrían estar produciendo interpretaciones contrarias a los criterios generales de la Ley.

Por último, en lo que a efectos urbanísticos nos interesa, la Ley pretende clarificar la situación actual del ejercicio de la actividad de intermediación inmobiliaria que se encuentra afectada por la falta de una jurisprudencia unánime que reconozca que dicha actividad no está reservada a ningún colectivo singular de profesionales. En este sentido el art. 3 de la Ley que comentamos, aclara que las actividades de intermediación inmobiliaria pueden ser ejercidas tanto por los Agentes de la Propiedad Inmobiliaria, como por cualquier persona física o jurídica sin necesidad de estar en posesión de título alguno, ni de pertenencia a ningún colegio oficial, sin perjuicio de los requisitos que, por razones de protección a los consumidores, establezca la normativa reguladora de esta actividad.

\section{MAYOR OBJETIVACIÓN DE LA CLASIFICACIÓN DEL SUELO NO URBANIZABLE E INCREMENTO DE LA OFERTA DE SUE- LO URBANIZABLE}

Para aumentar la oferta de suelo urbanizable, la nueva Ley 10/2003 da un nuevo paso en la línea ya trazada por la Ley 6/1998 y el Real Decreto-Ley 4/2000, es decir, pretende objetivar al máximo la clasificación del suelo no urbanizable, de tal manera que resulte más difícil otorgar dicha clasificación, con lo que debe crecer la bolsa de suelo urbanizable al ser éste ahora el residual. Recordemos que la Ley 6/1998, consagraba de manera altamente novedosa el carácter residual del suelo urbanizable. Hasta entonces el planeamiento determinaba lo que era el suelo urbano (por constatación de la realidad fáctica), clasificaba como urbanizable lo que estimaba oportuno según las 
necesidades previstas en el municipio, y el resto quedaba como suelo no urbanizable. Es decir, el suelo no urbanizable era el residual, dentro del cual podría distinguirse el suelo no urbanizable común, que no tenía valores objetivos que merecieran su protección, y de especial protección, cuando sus características naturales así lo reclamasen.

Ahora, desde la citada norma de 1998 el suelo urbanizable ha pasado a ser el residual, el común, lo cual supone fundamentalmente como novedad que el suelo no urbanizable hay que delimitarlo o definirlo en positivo, es decir, hay que motivar el porqué un suelo se clasifica como tal. Dejando de un lado el suelo no urbanizable de especial protección, que le viene impuesto al planificador urbanístico municipal por otros planes y normas de superior jerarquía, éste puede también preservar suelos como no urbanizables cuando constate que se dan en ellos determinados valores que impiden su urbanización. Estos valores estaban fijados en el art. 9.2 de la Ley 6/1998 de manera objetiva, a excepción del último de ellos, pues en un inciso final el precepto permitía la clasificación como no urbanizables de los suelos que "se considere inadecuados para un desarrollo urbano". Este último inciso dejaba la puerta abierta a criterios no muy objetivables en la clasificación de suelos como no urbanizables, con lo que el planeamiento general seguía disponiendo de gran capacidad de decisión, y la amplia discrecionalidad administrativa de difícil control encontraría respaldo en dicha expresión legal.

Para corregir esa puerta abierta, que hubo que dejar en virtud de los compromisos políticos necesarios para sacar la Ley adelante en el Parlamento, dado que el partido que había formado Gobierno únicamente tenía mayoría simple, en cuanto alcanzó dicha fuerza política la mayoría absoluta en las siguientes elecciones generales dictó rápidamente el Real Decreto-Ley 4/2000 en el que se eliminaba por completo el último inciso que acabamos de analizar el art. 9.2, de esta manera se objetivaban al máximo los criterios que podría determinar la clasificación de un suelo no urbanizable, para fomentar así el crecimiento de la bolsa de suelo urbanizable.

No obstante, a pesar de la intención del legislador estatal, la Sentencia del Tribunal Constitucional 164/2001, de 11 de julio, referida a la Ley 6/1998, relativizó enormemente las posibilidades de objetivación de los criterios para clasificar suelos como no urbanizables. La Sentencia dejaba abierta la puerta a que fuese la legislación autonómica la que concretara los valores o fines que serían determinantes de dicha clasificación. En base a estas posibilidades las distintas Leyes Autonómicas que se han ido dictando han sido muy laxas en la interpretación del 9.2, como ejemplo podemos poner el art. 46 de la Ley 
7/2002, de Ordenación Urbanística de Andalucía. Pues bien, la nueva Ley 10/2003 ha reformado el art. 9.2 de nuevo para recuperar el inciso antes eliminado, pero limitando la interpretación que cabe hacer del mismo, para evitar la aplicación de criterios altamente subjetivos en la clasificación del suelo no urbanizable.

En efecto, el precepto termina ahora diciendo que también pueden ser clasificados como no urbanizables los suelos "que se considere inadecuados para el desarrollo urbano, bien por imperativo del principio de utilización racional de los recursos naturales, bien de acuerdo con criterios objetivos de carácter territorial o urbanístico establecidos por la normativa urbanística". Como vemos se hace un esfuerzo por volver a dejar claro que no valen criterios subjetivos en la clasificación del suelo como no urbanizable. Es decir, no puede tratarse de una cuestión de opción sino de una constatación de que el suelo tiene o no tienen objetivamente unos valores que hacen inadecuada su transformación. Además, se llama a que la legislación urbanística autonómica concrete cuales pueden ser esos criterios objetivos territoriales o urbanísticos que pueden hacer que un suelo entre en la clasificación de no urbanizable. De esta manera se espera, de nuevo, que crezca la bolsa de suelo urbanizable, al no poder clasificar tanto suelo como no urbanizable, por no entrar en los parámetros objetivos de los que estamos hablando.

\section{AUMENTO DE LAS POSIBILIDADES DE TRANSFORMACIÓN DEL SUELO URBANIZABLE}

En la Ley 10/2003 se reforma el art. 15 de la Ley 6/1998, al añadirle un segundo párrafo al apartado segundo en el se deja claro que la transformación que pueden promover las Administraciones Públicas puede ser por razón de su titularidad dominical de suelo en el ámbito de que se trate, o bien por razones de simple competencia sectorial. De esta forma, se pretenden facilitar más aún las posibilidades de iniciativa pública en la transformación de los suelos urbanizables.

Con relación a este mismo tema del derecho a la transformación del suelo urbanizable, se ha aprovechado la reforma para introducir dos cambios interesantes en el art. 16, que recordemos recoge las reglas básicas para el ejercicio de dicho derecho:

a) En primer lugar, el apartado primero del precepto se ha modificado en cumplimiento de la Sentencia del Tribunal Constitucional 164/2001, que 
recordemos que lo había declarado nulo. El nuevo precepto queda dentro de los márgenes allí trazados de respeto a las competencias autonómicas al establecer que: "el derecho a promover la transformación del suelo urbanizable, mediante la presentación del planeamiento que corresponda o, en su caso, de la previa propuesta de delimitación del correspondiente ámbito para su tramitación y aprobación, se ejercerá de conformidad con lo establecido por la legislación urbanistica”.

b) En segundo lugar, se ha modificado el procedimiento previsto en el apartado tercero (introducido por el Real Decreto-Ley 4/2000) para la tramitación de planes de desarrollo que sean elaborados por las Administraciones Públicas a las que no competa su aprobación, o por los particulares. Ahora se aclara que los seis meses de silencio positivo se cuentan desde que el plan se presenta ante el órgano competente para su aprobación definitiva, y se exige para que la aprobación automática por silencio se produzca por imperio de la Ley que, además de haberse efectuado el trámite de información pública, se hayan solicitado los informes que sean preceptivos, según la legislación aplicable, y transcurrido el plazo para emitirlos.

\section{ACLARACIONES EN LOS PRECEPTOS RELATIVOS A VALORA- CIÓN DE SUELOS URBANOS Y URBANIZABLES, TENDENTES A EVITAR ELEMENTOS ESPECULATIVOS Y A SU CONTEN- CIÓN}

$\mathrm{Al}$ comprobar las modificaciones que se han introducido en los preceptos relativos a la valoración de suelos urbanos y urbanizables, tenemos rápidamente la sensación de que se están queriendo contener algunos abusos interpretativos que se entiende se estaban haciendo de los métodos de valoración de esas clases de suelos. Teniendo en cuenta que estos preceptos son aplicables para la valoraciones a efectos expropiatorios en todos los casos, puede concluirse que la Administración quiere evitar que muchas de las expropiaciones que realiza resulten excesivamente caras, en virtud de elementos especulativos y meras expectativas.

Las reformas introducidas en los artículos 27 y 28 de la Ley 6/1998 son fundamentalmente tres:

$\left.1^{\underline{a}}\right)$ Para el supuesto de suelos urbanizables se deja claro que "en cualquier caso, se descartarán los elementos especulativos del cálculo y aquellas expectativas cuya presencia no esté asegurada”. Así se ha entendido que la Administración no está para garantizar expectativas futuras que no están ya materializadas, ni hay ga- 
rantías de que así ocurra. Incluso para el caso de los suelos urbanizables que no estén incluidos por el planeamiento en ámbitos delimitados con condiciones para su desarrollo, se aclara que no se tendrá "consideración alguna de su posible utilización urbanistica".

$2^{a}$ ) Cuando se habla de inexistencia o pérdida de la vigencia de los valores de las ponencias catastrales, se aclara ahora, tanto para suelos urbanos como urbanizables, que también cabe su inaplicación "por modificación de las condiciones urbanísticas tenidas en cuenta al tiempo de su fijación”.

$\left.3^{\underline{a}}\right) \mathrm{Y}$, finalmente, aunque no debía ser necesario, se aclara para ambas clases de suelos, urbanos y urbanizables, que de los valores obtenidos de las ponencias de valores catastrales, hay que deducir siempre los gastos que establece el art. 30 de la Ley 6/1998, salvo que ya se hubieran deducido en su totalidad en la determinación de los valores en las ponencias. Tales gastos son los costes de la urbanización precisa y no ejecutada, y los de su financiación, gestión y, en su caso, promoción, así como los de las indemnizaciones procedentes o, en su defecto, los costes necesarios para que el terreno correspondiente alcance la condición de solar.

\section{ENTRADA EN VIGOR Y TRANSITORIEDAD}

Estas son las líneas generales de la reforma operada por la Ley 10/2003 sobre la Ley 6/1998, que entró en vigor al día siguiente de su publicación, es decir el 22 de mayo de 2003.

En sus disposiciones transitorias se prevé que el planeamiento general se adapte a la reforma relativa a la clasificación del suelo de conformidad con el régimen transitorio establecido en la legislación urbanística en cada caso, y, únicamente en ausencia de éste, se realice dicha adaptación en la siguiente revisión, para el supuesto de planeamiento vigente o cuando se tramiten modificaciones en el mismo que afecten a la clasificación del suelo, y, para el caso de planes en tramitación, siempre, con independencia de la fase en que se encuentre la misma.

Las disposiciones sobre valoraciones serán aplicables en los expedientes expropiatorios en los que no se haya alcanzado aún la fijación definitiva del justiprecio en vía administrativa. 